Canadian Journal of Civil Engineering

Canadian

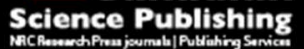

Revue canadienne de génie civil

\title{
Experimental and Numerical Investigation of Lateral Torsional Buckling of Wood I-Joists
}

\begin{tabular}{|r|l|}
\hline Journal: & Canadian Journal of Civil Engineering \\
\hline Manuscript ID & cjce-2017-0281.R1 \\
\hline Manuscript Type: & Article \\
\hline Date Submitted by the Author: & 27-Aug-2017 \\
\hline $\begin{array}{r}\text { Complete List of Authors: } \\
\begin{array}{r}\text { Is the invited manuscript for } \\
\text { consideration in a Special } \\
\text { Issue? : }\end{array}\end{array}$ & $\begin{array}{l}\text { St-Amour, Rémi ; University of Ottawa } \\
\text { Doudak, Ghasan; University of Ottawa, }\end{array}$ \\
\hline Keyword: & $\begin{array}{l}\text { Wood I-joist, Engineered wood product, lateral instability, lateral torsional } \\
\text { buckling, finite element analysis, non-linear anal }\end{array}$ \\
\hline &
\end{tabular}




\section{Experimental and Numerical Investigation of Lateral}

\section{Torsional Buckling of Wood I-Joists}

3 Rémi St-Amour ${ }^{1}$, Ghasan Doudak ${ }^{2}$

4 Abstract This paper investigates the elastic lateral torsional buckling capacity of wood

5 I-joists. A sensitivity analysis determined that the orthotropic material properties that

6 affect the critical buckling load of wood I-joists are the longitudinal modulus of elasticity,

7 the transverse shear modulus of the flanges and the elastic modulus of the web. A 3D

8 finite element model was developed using experimentally determined material properties

9 and initial imperfections. The study found that FE linear predictions provided reasonable

10 agreement with the experimental buckling loads. The FE geometric nonlinear analysis

11 was able to replicate the experimental nonlinear behavior that was observed during the

12 test. Comparison with contemporary North American design standards showed

13 significant conservatism in the design approach.

14 Keywords Wood I-joist, Engineered wood product, lateral instability, lateral torsional

15 buckling, finite element analysis, non-linear analysis, initial imperfection, full-scale 16 testing.

\footnotetext{
${ }^{1}$ MASc student, Dept. of Civil Engineering, Univ. of Ottawa, ON, Canada K1N 6N5.

${ }^{2}$ Associate Professor, Dept. of Civil Engineering, Univ. of Ottawa, Ottawa, ON, Canada K1N 6N5. (corresponding author) E-mail: gdoudak@uottawa.ca
} 


\section{Introduction}

18 The slender nature of wood I-joists may be desirable for flexural resistance but comes at

19 the price of lateral instability as they become susceptible to lateral torsional buckling

20 (LTB) failure. An I-shaped beam develops a tendency to undergo lateral torsional

21 buckling when it is bent about its major axis, if it is not restrained against lateral and

22 angular displacements. Several examples of construction details exist where wood I-joists

23 may not be adequately braced, such as continuous beams, cantilevers and design cases

24 where wind uplift on roofs governs the design.

25 North American timber design standards consider lateral torsional buckling as a potential

26 failure mode for long and slender members. The development of present provisions on

27 the lateral torsional buckling of rectangular wood beams is based on the work by Hooley

28 \& Madsen (1964). Research by Bell and Eggen (2001), Suryoatmono and Tjondro

29 (2008), Hindman (2005a), and Xiao (2014) validated the lateral buckling provisions

30 through experimental and numerical investigations. The stability of more complex

31 systems such as beam and deck assemblies were also assessed through numerical studies

32 including those by Zahn (1973) and Du et al. (2016).

33 A closed form solution for the lateral torsional buckling of an I-beam was originally

34 derived for a simply supported configuration and a uniform moment based on the

35 principle of total potential energy (Timoshenko \& Gere 1961). The critical moment $M_{c r}$

36 for a simply supported I-beam of unsupported length $L$, weak-axis bending stiffness $E I_{y}$, 
37 torsional rigidity $G J$ and a warping stiffness $E C_{w}$ subjected to a uniform moment $M$ is 38 given as:

$$
M_{c r}=\frac{\pi}{L} \sqrt{E I_{y} G J+\left(\frac{\pi E}{L}\right)^{2} I_{y} C_{w}}
$$

40 Several factors influence the lateral torsional buckling resistance of an I-section,

41 including the section geometric properties, moment distribution along the span, boundary

42 conditions and the position of the applied load relative to the shear center. Closed form

43 solutions for boundary conditions, moment distribution and load eccentricity effect other

44 than those assumed for Equation 1 are often unattainable using closed form solutions.

45 Finite element analysis can be used to find the critical moment of such configurations,

46 and factors can be derived for various moment gradient $\left(C_{m}\right)$ and load positions relative

47 to the shear center $\left(C_{e}\right)$.

48 An underlying assumption of Eq. 1 is that it is based on a homogenous material, whereas

49 wood I-joists consists of a composite assembly of wooden flanges, usually made of

50 machine stress-rated lumber or laminated veneer lumber, and a web panel made of

51 oriented strand board (OSB). Transformed section properties, including St-Venant

52 constant, $J_{t r}$, warping constant, $C_{w t r}$, and moment of inertia about the weak axis, $I_{y t r}$,

53 for composite I-sections with different materials for the flanges and the web can be

54 derived from the theorem of internal strain energy and Vlasov theory ( $\mathrm{Du} 2016$ ). An

55 analytical solution is derived (Eq. 2) to predict the critical buckling load of the wood I- 
56 joists by including the moment gradient and load eccentricity factors $\left(C_{m} C_{e}\right)$ as well as

57 the transformed section properties $\left(E I_{y t r}, G J_{t r}\right.$ and $C_{w}$ tr $)$ :

$$
M_{c r}=C_{m} C_{e} \frac{\pi}{L} \sqrt{E I_{y t r} G J_{t r}+\left(\frac{\pi E}{L}\right)^{2} I_{y t r} C_{w t r}}
$$

59 In the derivation of Eq. 2, it was assumed that the section is made of isotropic material.

60 However, wood is an anisotropic material but can be simplified and modelled as a

61 rectangular orthotropic material (Isopescu et al. 2012). Also, it has been demonstrated

62 that only 2 of the 9 orthotropic properties of wood influence the elastic lateral torsional

63 buckling response of solid sawn wooden beams (Xiao et al. 2014), namely the

64 longitudinal modulus of elasticity and the transverse shear modulus. Material properties

65 of engineered wood products has been investigated by Hindman (2005a) including the

66 modulus of elasticity and the shear modulus of machine stress-rated lumber, laminated-

67 veneer lumber, parallel strand lumber, and laminated strand lumber.

68 Although experimental data on the modulus of elasticity and the shear modulus of OSB

69 panel has been provided in the literature (e.g. Hindmann 2003, FPL 2010, Thomas 2011),

70 little is known about the torsional shear modulus and the Poisson's ratio. Grandmont

71 (2011) studied the effect that the material properties of the web has on the deflection of

72 wood I-joist using a finite element model. It was demonstrated that the density variations

73 along the OSB panels affect the shear resistance of wood I-joist and that the properties

74 determined from small-scale specimens differed significantly from those of large scale 
75 specimens. No consistency is found in the literature on how to experimentally determine

76 the material properties of wood I-joists for model input.

77 Hindman (2005b) conducted an experimental study on the lateral buckling of 78 cantilevered wood I-joist subjected to a concentrated force at the free end. The author 79 showed that the elastic buckling beam theory (Timoshenko \& Gere 1961) yielded 80 reasonably accurate results, although there was a significant difference in the range of 12 81 to $43.4 \%$. Differences were attributed to considering wood I-joist as a homogenous 82 isotropic material. Zhu et al. (2005) studied the buckling behavior of wood I-joists by 83 comparing experimental tests to finite element simulations in ABAQUS. An empirical

84 formula was derived for the buckling capacity of the web. The authors concluded that the 85 global buckling of wood I-joist was driven by the span, flange size and the location of 86 lateral restraints. Finite element model including geometrical non-linearity provided 87 predictions that agreed well with experimental data. The findings by Zhu et al. (2005) 88 support what was stated previously by Kirby and Nethercot (1979) that initial geometric 89 imperfections reduce the load-carrying capacity of thin-walled members and that effects

90 on the nonlinear response becomes larger with increase in initial imperfections.

91 Burow et al. (2006) investigated the behavior of wood I-joists in lateral buckling through 92 cantilever and simply supported configurations. Three mathematical models were 93 developed and they included various loading and lateral bracing configurations. Bending 94 stiffness and torsional rigidity of the wood I-joists were determined experimentally. 95 Aguilar (2012) investigated the lateral buckling behavior of wood I-joists under human 
96 walking loads. The author concluded that the critical buckling loads were influenced by

97 the end support condition and the location of the braces. Hindman et al. (2014) studied

98 the effect of bracing stiffness, and human participants' weight on the lateral torsional

99 buckling behavior of wood I-joist. The study showed that the brace stiffness inhibited the

100 angular and lateral displacements of the wood I-joists, while the brace configuration did

101 not influence the lateral acceleration.

102 The current research study aims at expanding the knowledge base on the lateral

103 instability of engineered wood I-joists through full-scale testing and numerical analysis of

104 deeper and longer specimens than was found in the literature. The objective of the study

105 is to develop a finite element model with experimentally determined material properties

106 and initial imperfections to predict the behavior of wood I-joist tested in full-scale. The

107 paper also evaluates the adequacy of current timber code provisions on lateral stability of

108 engineered wood I-joists.

\section{Sensitivity analysis}

110 Prior to the commencement of the experimental program, a sensitivity analysis was

111 conducted to determine the parameters that significantly influence the lateral torsional

112 buckling behavior of wood I-joists. S4R shell elements were used for modeling the I-joist

113 web. This general-purpose element considers transverse shear deformation for thick shell,

114 however, it becomes negligible when the shell thickness is small. It has a total of 24

115 degrees of freedom per element (3 displacement and 3 rotation components per node). 
116 Solid C3D8R elements were considered for the I-joist flanges, featuring a solid brick that

117 consists of 24 degrees of freedom ( 3 translational degrees of freedom per node) with

118 reduced integration and hourglass control. These elements have previously been used in

119 the literature to model solid wood beams and wood I-joists (e.g. Zhu 2005 and Xiao

120 2014). The wood I-joists were composed of solid-sawn lumber and oriented strand board

121 web, which are both modelled as rectangular orthotropic elastic materials. Table 1

122 presents the material properties of the reference case. The flange properties are based on

123 the species Sitka Spruce, while the properties of the web are based on mean values found

124 in the literature (FPL 2010 and Thomas 2010). In Table 1, $E_{i}, G_{i}$ and $\mu_{i}$ denotes the

125 modulus of elasticity, shear modulus and Poisson's ratio in the $i^{\text {th }}$ direction as illustrated

126 in Figure 1.

127 Table 1: FE Material properties for the reference case in the sensitivity analysis

\begin{tabular}{|l|l|l|}
\hline Material property & Flanges & Web \\
\hline $\mathrm{E}_{1}(\mathrm{MPa})$ & 11200 & 2500 \\
\hline $\mathrm{E}_{2}(\mathrm{MPa})$ & 678 & 5000 \\
\hline $\mathrm{E}_{3}(\mathrm{MPa})$ & 678 & 500 \\
\hline$\mu_{12}(\mathrm{MPa})$ & 0.372 & 0.195 \\
\hline$\mu_{13}(\mathrm{MPa})$ & 0.467 & 0.195 \\
\hline$\mu_{23}(\mathrm{MPa})$ & 0.435 & 0.195 \\
\hline $\mathrm{G}_{12}(\mathrm{MPa})$ & 700 & 500 \\
\hline
\end{tabular}




\begin{tabular}{|l|l|l|}
\hline $\mathrm{G}_{13}(\mathrm{MPa})$ & 700 & 500 \\
\hline $\mathrm{G}_{23}(\mathrm{MPa})$ & 33.6 & 100 \\
\hline
\end{tabular}

128 Figure 1 illustrates the inactive translational degrees of freedom (DOFs) at the member

129 ends that provide a pinned-roller support in the transverse (axis 2) and lateral (axis 3)

130 directions as well as rotation restrain about the longitudinal axis (axis 1). The web-to-

131 flange connectivity nodes share the same DOFs using the "SHELL TO SOLID

132 COUPLING" feature in ABAQUS. This feature is used to couple the displacement and

133 rotation DOFs of the shell nodes to the solid surface at the web-to-flange interface, which

134 helps document the effect of distortion of the web on the buckling capacity of the

135 I-joist. 

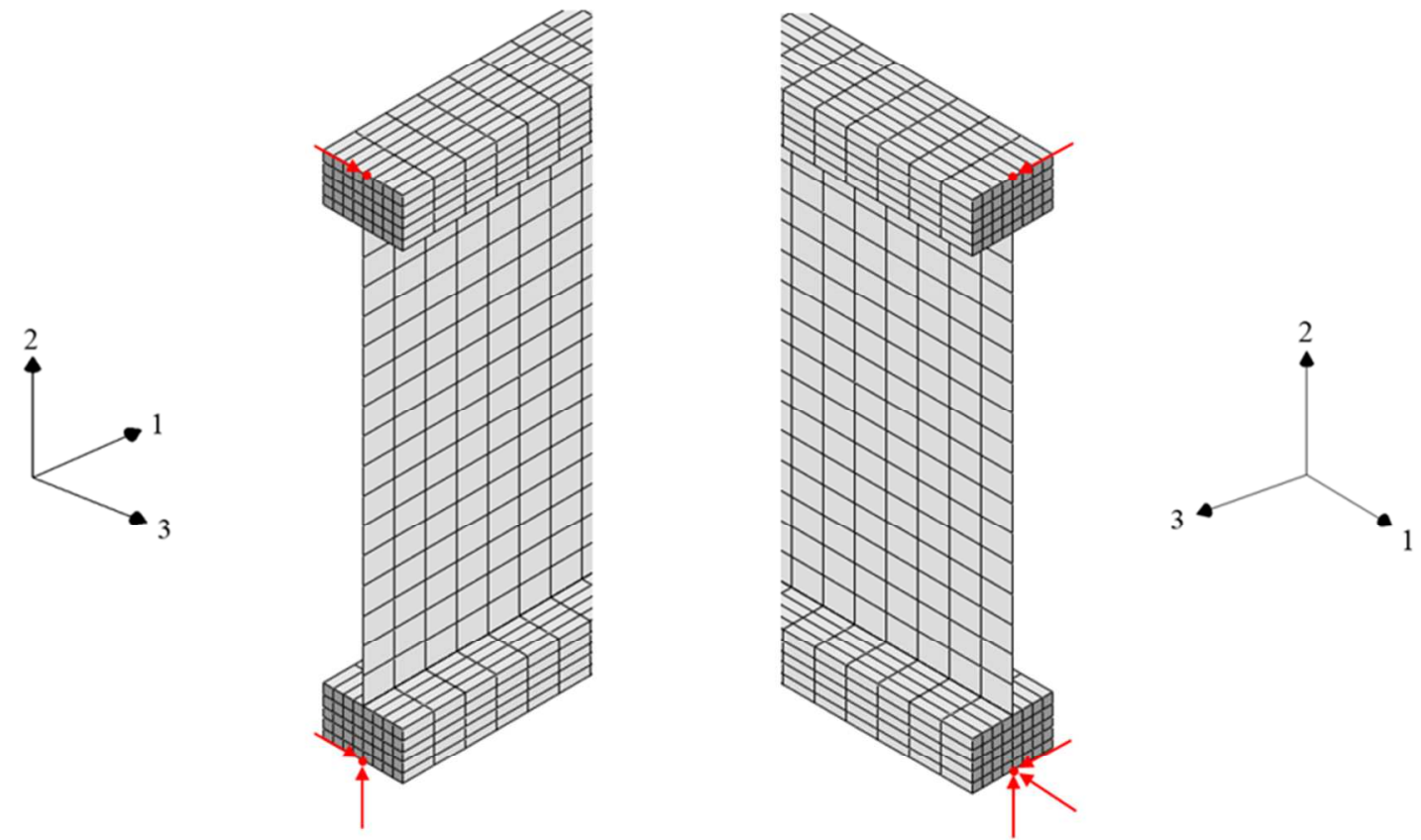

136 Figure 1 Inactive translational DOFs (RED arrows) at each end of a simply supported wood I-joist

138 The load application consisted of a uniform moment about the strong axis. This was done

139 using concentrated forces that were applied at the boundary nodes of the flanges resulting

140 in compression in the top flange and tension in the bottom flange. An eigenvalue

141 buckling analysis was performed to evaluate the critical load. Mesh sensitivity indicated

142 that the critical load converges when using 232 elements along the length, eight elements

143 for the flange width, five elements across the flange thickness and 16 elements for the 144 web height. Further mesh refinements did not result in significant improvement of the 145 solution convergence. 
146 The buckling capacity obtained from the finite element (FE) model was analyzed for each

147 parameter by varying the reference value (from Table 1) from $50 \%$ to $150 \%$, while

148 keeping all other material parameters constant, as shown in Table 2. The effects of

149 varying these parameters on the buckling capacity are shown as a ratio of the critical

150 moment obtained for each case to that of the reference case.

151 Table $2 \mathrm{FE}$ model buckling capacity response to material properties fluctuations

\begin{tabular}{|c|c|c|c|c|c|c|c|c|c|c|c|c|}
\hline \multirow[b]{2}{*}{ 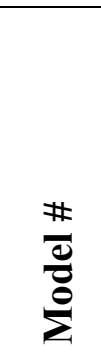 } & \multicolumn{9}{|c|}{ Material property fluctuation } & \multicolumn{3}{|c|}{$\mathbf{M}_{\mathrm{cr}} / \mathbf{M}_{\mathrm{cr}-\mathrm{ref}}$} \\
\hline & 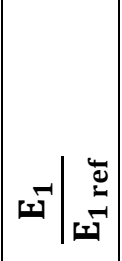 & N⿴囗十 & 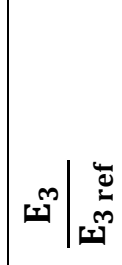 & 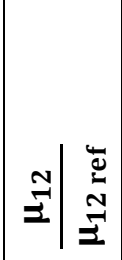 & 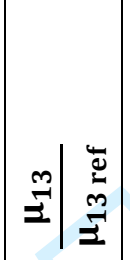 & 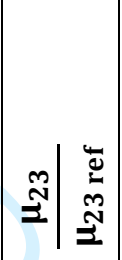 & जै| & जै| & ज્ञ & 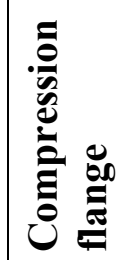 & 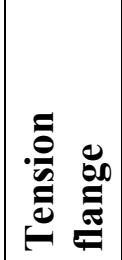 & ह \\
\hline Ref. & 1 & 1 & 1 & 1 & 1 & 1 & 1 & 1 & 1 & 1.00 & 1.00 & 1.00 \\
\hline 1 & 1.5 & 1 & 1 & 1 & 1 & 1 & 1 & 1 & 1 & 1.24 & 1.04 & 1.00 \\
\hline 2 & 0.5 & 1 & 1 & 1 & 1 & 1 & 1 & 1 & 1 & 0.75 & 0.94 & 1.00 \\
\hline 3 & 1 & 1.5 & 1 & 1 & 1 & 1 & 1 & 1 & 1 & 1.00 & 1.00 & 1.02 \\
\hline 4 & 1 & 0.5 & 1 & 1 & 1 & 1 & 1 & 1 & 1 & 1.00 & 1.00 & 0.97 \\
\hline 5 & 1 & 1 & 1.5 & 1 & 1 & 1 & 1 & 1 & 1 & 1.00 & 1.00 & 1.00 \\
\hline 6 & 1 & 1 & 0.5 & 1 & 1 & 1 & 1 & 1 & 1 & 1.00 & 1.00 & 1.00 \\
\hline 7 & 1 & 1 & 1 & 1.5 & 1 & 1 & 1 & 1 & 1 & 1.00 & 1.00 & 1.00 \\
\hline 8 & 1 & 1 & 1 & 0.5 & 1 & 1 & 1 & 1 & 1 & 1.00 & 1.00 & 0.99 \\
\hline 9 & 1 & 1 & 1 & 1 & 1.5 & 1 & 1 & 1 & 1 & 1.00 & 1.00 & 1.00 \\
\hline 10 & 1 & 1 & 1 & 1 & 0.5 & 1 & 1 & 1 & 1 & 1.00 & 1.00 & 1.00 \\
\hline 11 & 1 & 1 & 1 & 1 & 1 & 1.5 & 1 & 1 & 1 & 1.00 & 1.00 & 1.00 \\
\hline 12 & 1 & 1 & 1 & 1 & 1 & 0.5 & 1 & 1 & 1 & 1.00 & 1.00 & 1.00 \\
\hline 13 & 1 & 1 & 1 & 1 & 1 & 1 & 1.5 & 1 & 1 & 1.02 & 1.02 & 1.01 \\
\hline 14 & 1 & 1 & 1 & 1 & 1 & 1 & 0.5 & 1 & 1 & 0.96 & 0.96 & 0.99 \\
\hline 15 & 1 & 1 & 1 & 1 & 1 & 1 & 1 & 1.5 & 1 & 1.05 & 1.05 & 1.00 \\
\hline 16 & 1 & 1 & 1 & 1 & 1 & 1 & 1 & 0.5 & 1 & 0.92 & 0.92 & 1.00 \\
\hline 17 & 1 & 1 & 1 & 1 & 1 & 1 & 1 & 1 & 1.5 & 1.00 & 1.00 & 1.00 \\
\hline
\end{tabular}




\begin{tabular}{|l|l|l|l|l|l|l|l|l|l|l|l|l|}
\hline 18 & 1 & 1 & 1 & 1 & 1 & 1 & 1 & 1 & 0.5 & 0.99 & 0.99 & 0.99 \\
\hline
\end{tabular}

152 From Table 2, it can be concluded that the most sensitive parameter is the modulus of

153 elasticity of the compression flange in the longitudinal direction $\left(E_{1}\right)$. The shear modulus

154 of the flanges $\left(\mathrm{G}_{12}\right.$ and $\left.\mathrm{G}_{13}\right)$, also play a significant role in the lateral buckling response.

155 Such results are consistent with the classical theory. Additionally, the FE sensitivity

156 analysis indicates a moderate effect of web distortion on the buckling capacity. The

157 modulus of elasticity (MOE) and shear modulus in the remaining planes as well as the

158 Poisson's ratios had no effect on the buckling capacity. The above formed the basis for

159 the material parameters that were determined experimentally.

160 Experimental program

\section{Component tests and determining model inputs}

162 Two approaches were considered to investigate the longitudinal elastic modulus and

163 shear modulus of the I-joists' flanges, namely those involving the whole I-joist or

164 considering flange components alone. Figure 2 illustrates the dimensions for the two I-

165 joist cross sections investigated.

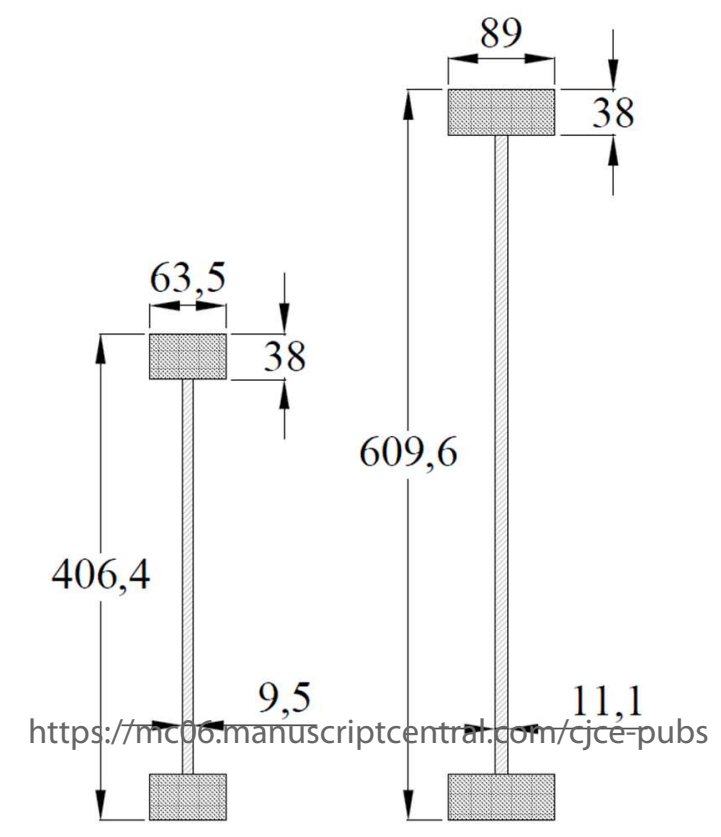


178 The determination of the flanges' longitudinal modulus of elasticity involved subjecting

179 both the whole I-joist as well as the flange components to bending tests in accordance

180 with the ASTM standard (D198-14). Specimens were loaded to $25 \%$ of the estimated 181 elastic limit at a prescribed rate of $20 \mathrm{~mm} /$ minute. The flanges were supported at each

182 end with bearing plates to allow unrestricted longitudinal deformation and rotation during 183 the loading phase. The MOE resulting from the lateral flexural tests on whole I-joist were 184 compared to the one obtained from their respective flanges. The results yielded a 185 difference in the range of 3 to $11 \%$. This difference is likely due to the fact that the 186 component testing approach used only half of the flange length, while the lateral flexural 187 test used the whole flange length. Both methods showed similar variability in the 188 resulting MOE values. Given the similarities in the results it can be assumed that both test 189 methods could be used to derive the model inputs for MOE. The MOE results from the 190 entire I-joist was used as input in the current study since it involves the whole wood I191 joist specimen length, and thus accounts for the strength variations along the flanges. 
192 Furthermore, the bending deformations takes place at the same critical section as for the

193 lateral torsional buckling tests.

194 The determination of the flanges' transverse shear modulus also involved subjecting the

195 whole I-joist or the flange components to torsion tests. The torsion test procedure

196 followed the ASTM standard (D198-14), as shown in Figure 3. Inclinometers were used

197 to measure the angle of twist. The loading was applied until the specimen reached

198 approximately $8^{\circ}$ angle of twist to avoid any inelastic deformation.

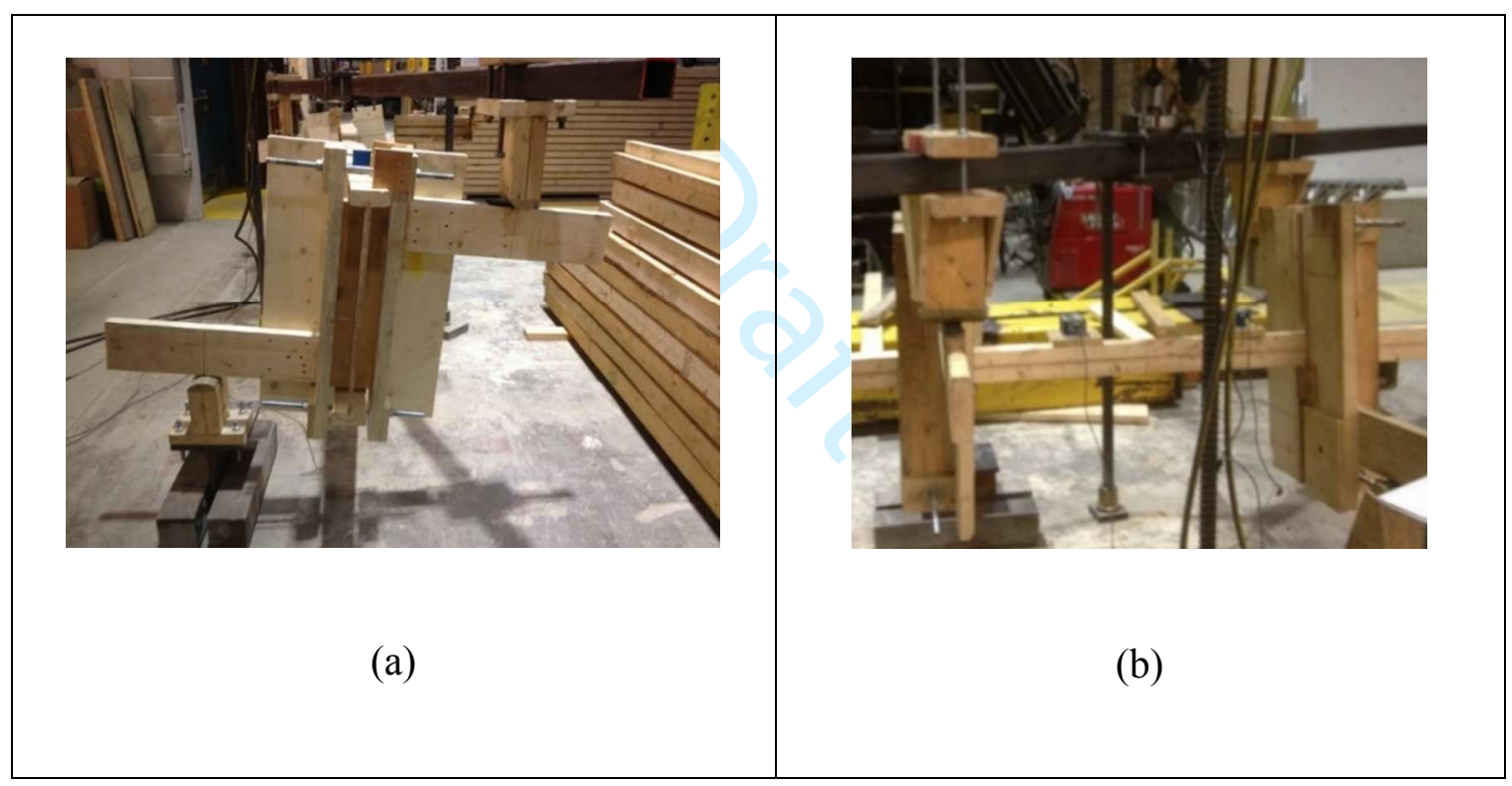

199 Figure 3 I-joist torsional rigidity test configuration for whole I-joist (a) and the flange only (b)

201 The transverse modulus of elasticity of the web was determined based on the procedure 202 described in the American Standard Test Methods for panel in flexure (D3043). A point 203 load was applied at the mid-span of a simply supported web test specimen. The web 
204 specimen was cut from selected I-joists after the lateral torsional buckling test was

205 conducted. These specimens were taken from regions near the support to avoid any

206 damage that may have occurred from the previous test.

207 Full scale lateral torsional buckling capacity

208 The lateral torsional buckling capacity of 42 I-joists specimens of various dimensions

209 (Table 3) was evaluated using a simply supported beam configuration with a concentrated

$210 \quad$ load applied at mid-span on the specimen top flange (Figure 4

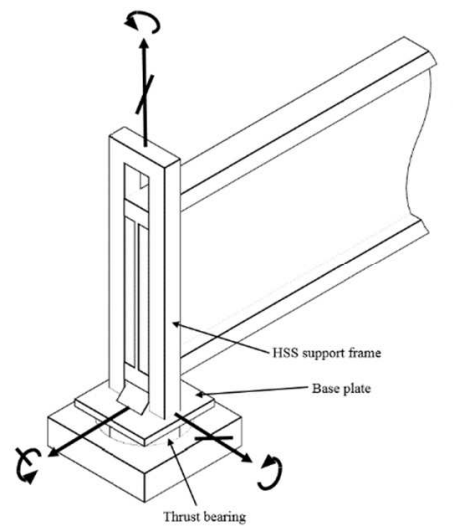

212 (a)). In Table 3, IB stands for bending tests on whole I-joists, CT is for component testing

213 which involves bending tests on the flanges, torsion tests on the flanges and bending tests

214 on the webs. LTB represents full-scale lateral torsional buckling test and IT indicates

215 torsion test on whole I-joists.

216 Table 3: Wood I-joist specimen breakdown and moisture content

\begin{tabular}{|l|c|c|c|c|c|c|}
\hline $\begin{array}{l}\text { Sample } \\
\text { group \# }\end{array}$ & $\begin{array}{c}\text { Specimen } \\
\text { length } \\
\text { m [feet] }\end{array}$ & $\begin{array}{c}\text { I-joist } \\
\text { section } \\
\text { depth, } m\end{array}$ & $\begin{array}{c}\text { Number } \\
\text { of } \\
\text { specimens }\end{array}$ & $\begin{array}{c}\text { Average } \\
\text { moisture } \\
\text { content } \\
(\%)\end{array}$ & $\begin{array}{c}\text { Moisture } \\
\text { content } \\
\text { COV } \\
(\%)\end{array}$ & $\begin{array}{c}\text { Test } \\
\text { conducted }\end{array}$ \\
\hline
\end{tabular}




\begin{tabular}{|c|c|c|c|c|c|c|}
\hline 1 & $1.83[6]$ & 0.4 & 10 & 12.7 & 4.67 & IB, CT \\
\hline 2 & $2.44[8]$ & 0.4 & 10 & 13.0 & 7.03 & IB, \\
\hline 3 & $3.05[10]$ & 0.4 & 10 & 12.6 & 5.51 & IB, \\
\hline 4 & $3.66[12]$ & 0.4 & 10 & 12.8 & 6.48 & IB, \\
\hline 5 & $4.27[14]$ & 0.4 & 10 & 12.6 & 2.73 & $\begin{array}{c}\text { IB, LTB, } \\
\text { CT }\end{array}$ \\
\hline 6 & $4.88[16]$ & 0.4 & 5 & 12.8 & 4.57 & IB, IT, LTB \\
\hline 7 & $5.49[18]$ & 0.4 & 5 & 12.5 & 2.13 & IB, IT, LTB \\
\hline 8 & $6.10[20]$ & 0.4 & 26 & 12.6 & 3.52 & $\begin{array}{c}\text { IB(11), IT, } \\
\text { LTB }\end{array}$ \\
\hline 9 & $1.83[6]$ & 0.6 & 10 & 15.8 & 4.61 & IB, \\
\hline 10 & $2.44[8]$ & 0.6 & 10 & 15.9 & 6.69 & IB, \\
\hline 11 & $3.05[10]$ & 0.6 & 10 & 14.8 & 6.23 & IB, \\
\hline 12 & $3.66[12]$ & 0.6 & 10 & 16.0 & 6.99 & IB, \\
\hline 13 & $4.27[14]$ & 0.6 & 10 & 15.3 & 2.96 & IB, \\
\hline 14 & $4.88[16]$ & 0.6 & 5 & 15.3 & 7.34 & IB, \\
\hline 15 & $5.49[18]$ & 0.6 & 5 & 15.5 & 4.14 & IB, \\
\hline 16 & $6.10[20]$ & 0.6 & 11 & 15.4 & 7.15 & IB, IT, \\
\hline
\end{tabular}

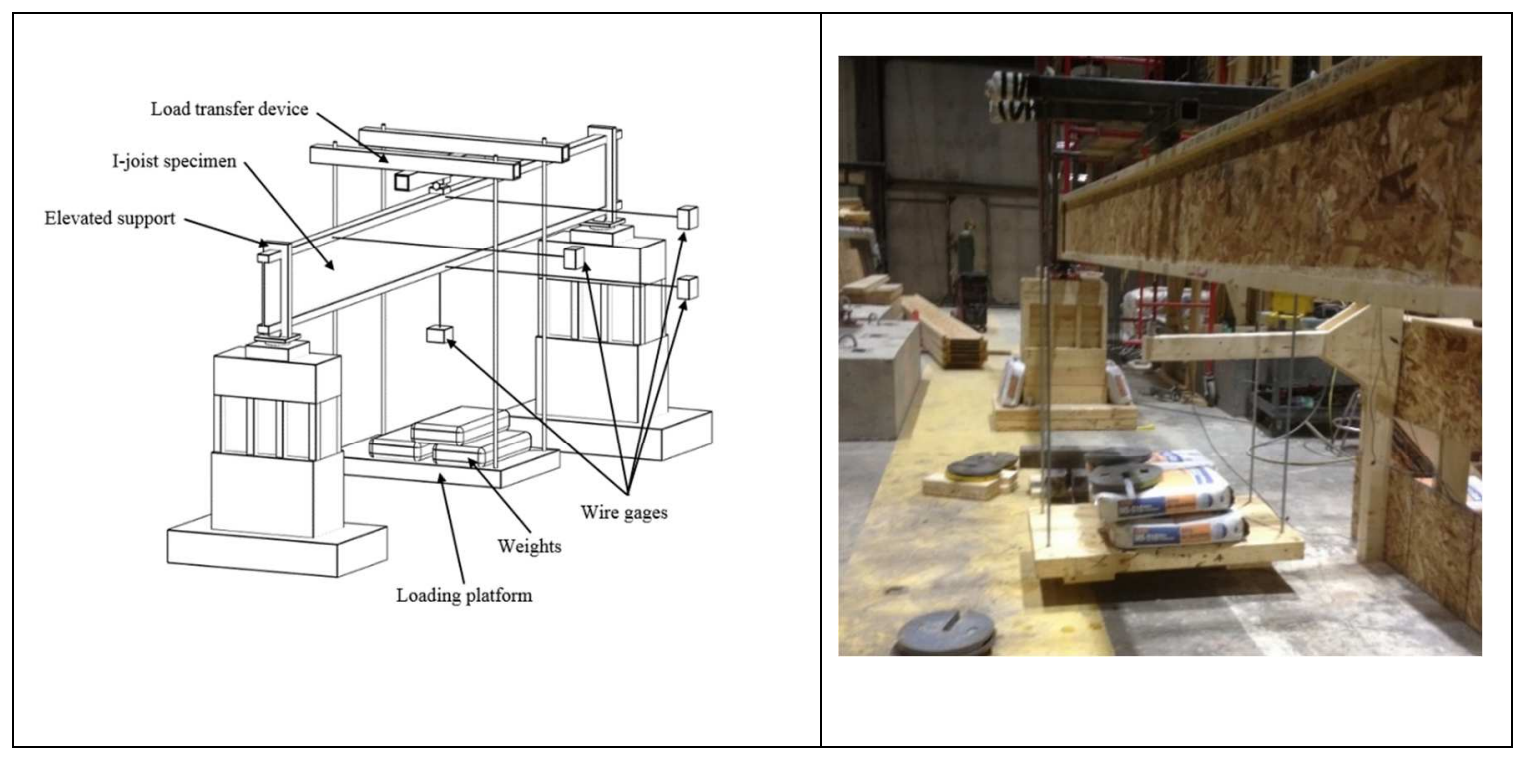




\section{(a)}

(b)

218 Figure 4: Schematic drawing of the full-scale lateral torsional buckling test setup (a) and load transfer device (b)

220 The initial out-of-straightness of the top flange was documented prior to testing.

221 Measurements taken during the test consisted of mid-height lateral deflection at mid-

222 span, vertical displacement at mid-span, angular displacement at mid-span and lateral

223 deflection of the top flange at quarter-span. The test specimen was loaded manually by

224 adding weights on a loading platform attached to a load transfer device mounted on the

225 top flange. This allowed the loading apparatus to follow the I-joist through its buckling

226 motion without providing any lateral restraint. The end supports were designed to restrain

227 the vertical displacement, lateral displacement, and rotation about the I-joist longitudinal

228 axis. To that purpose, the specimen was confined in an HSS frame preventing vertical

229 and lateral displacement as well as rotation about the longitudinal axis (Figure 5). The

230 frame was placed on a thrust bearing to allow the specimen to rotate freely about the

231 vertical axis. A steel shaft, welded to the frame base plate, was inserted through the thrust

232 bearing into a steel base that had a fitted hole to prevent the HSS frame from translating

233 in the lateral-longitudinal plane (Figure 5). The load transfer device was designed to

234 transmit the load from the loading platform to the top flange as a concentrated force. A

235 steel hinged support allowed the load to remain vertical during the buckling motion of the

236 test specimen, which is consistent with the underlying assumptions of the reference case

237 for lateral torsional buckling. To achieve this configuration, the hinged support bottom 
238 was screwed on the specimen top flange while the upper part was welded to the load 239 transfer device.

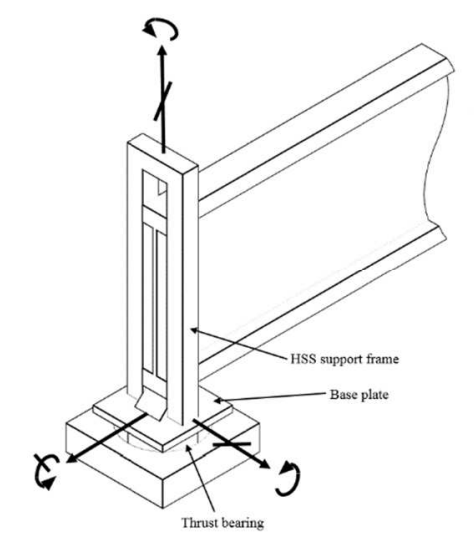

(a)

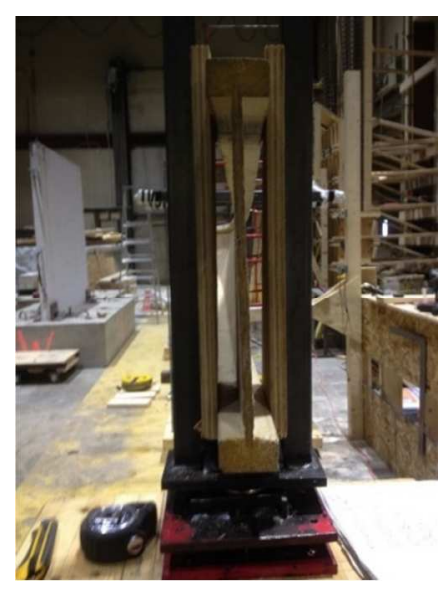

(b)

241 Figure 5: Schematic drawing of end supports design and its restrained DOFs (a) and actual testing end support (b)

243 Figure 6 shows the buckling motion of the I-joist specimen during the loading phase.

244 Most of the test specimen started deflecting laterally as soon the loading was applied.

245 Very few specimens remained straight during the loading phase until they reached their 246 lateral torsional buckling capacity. 


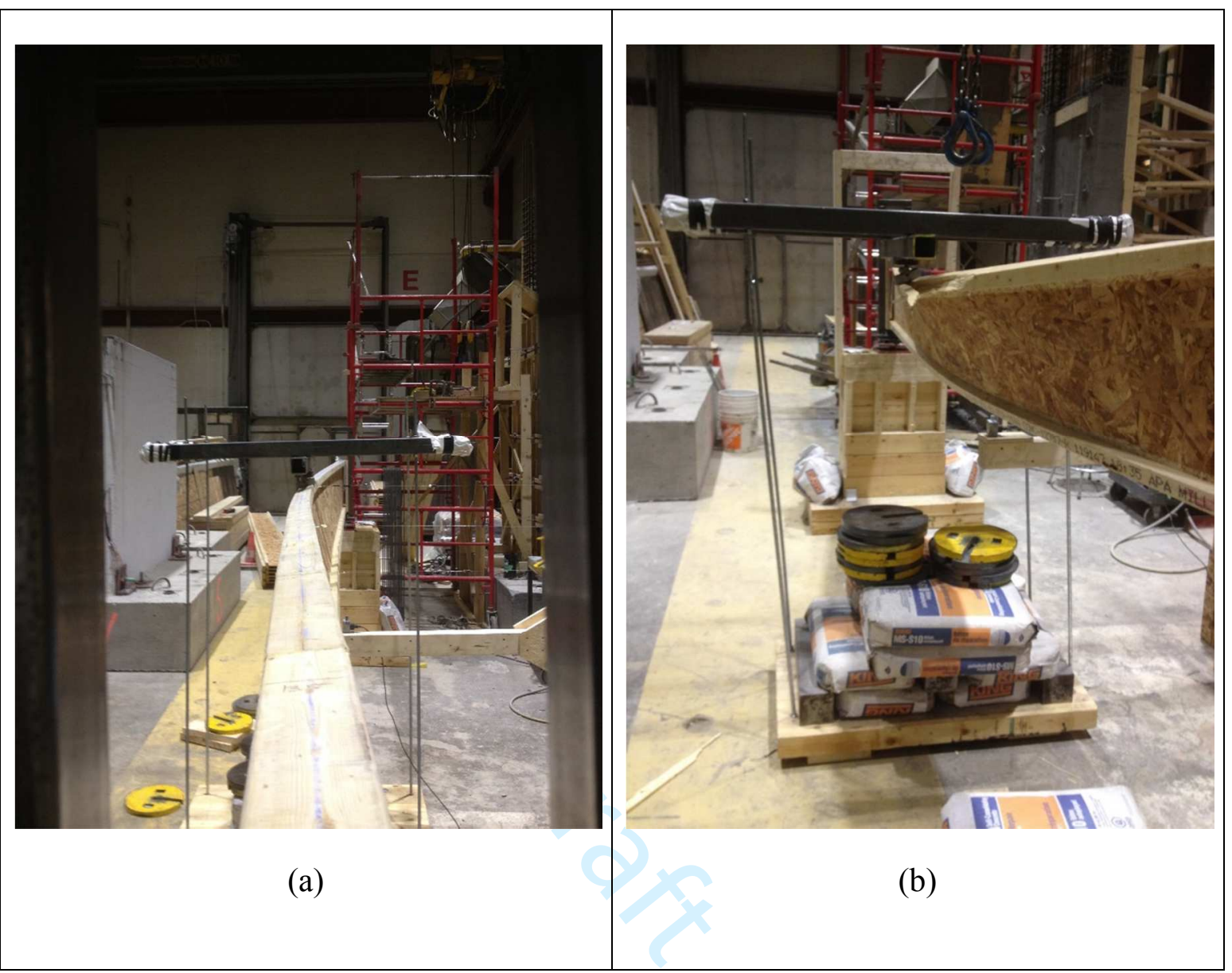

248 Figure 6 Lateral torsional buckling test deformations. (a) buckling shape, (b) ultimate material failure reached.

250 Figure 7 displays the buckling shape of eight specimens which are representative of the

251 observed force-displacement curves in the current study. The results reveal two lateral

252 torsional buckling deformation behaviors, one where the I-joist behaves as a perfectly

253 straight beam undergoing lateral torsion buckling when reaching its critical buckling

254 load, and another where the behavior is nonlinear due majorly to initial imperfections. It 
255 can be observed that the nonlinear buckling shapes will generally fail in the vicinity of 256 the critical buckling load of those that exhibited a linear behavior.

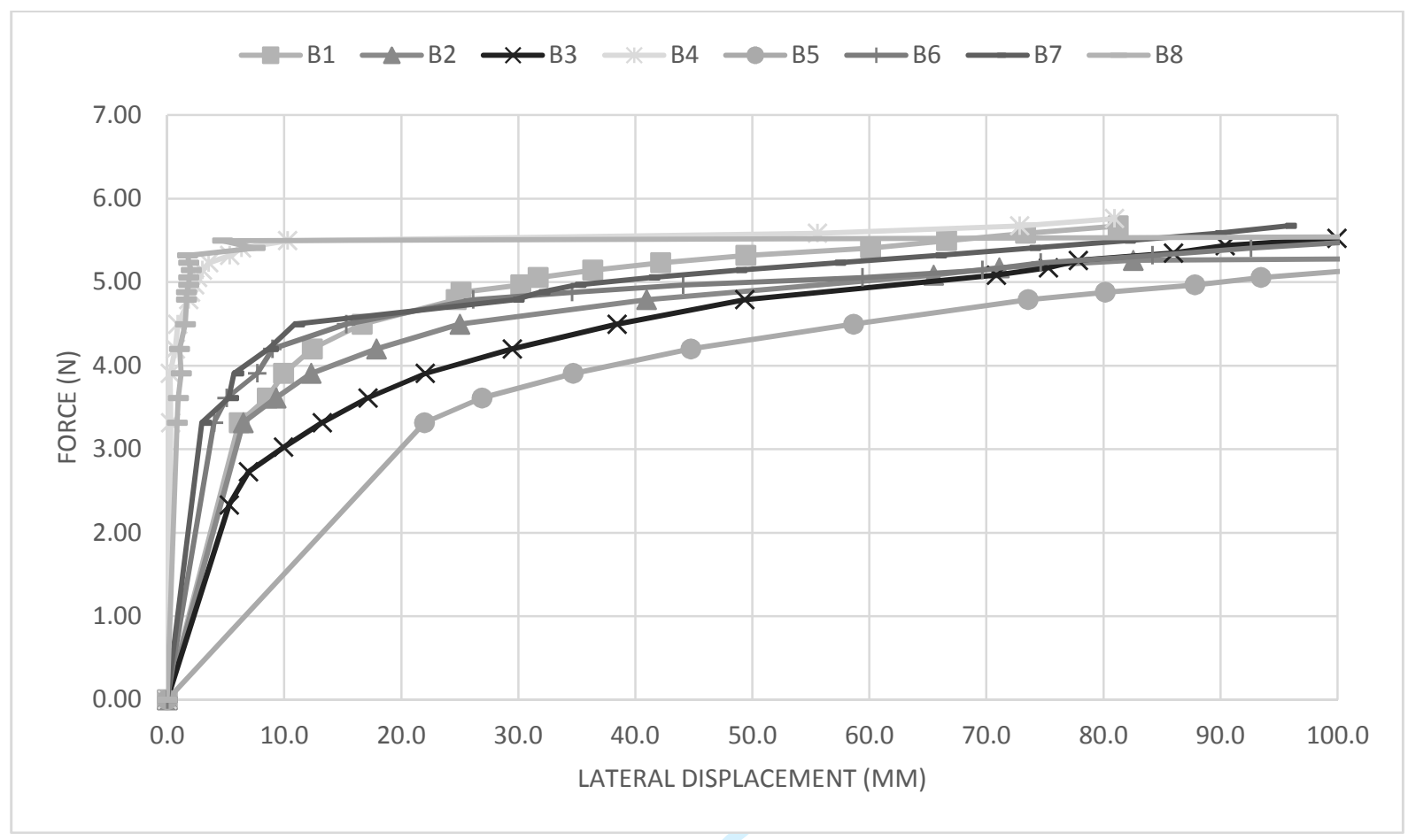

Figure 7 : Experimental lateral buckling behavior of wood I-joist specimen from sample group \#16

261 Flexural capacity

262 The flexural capacity was also evaluated in accordance with the ASTM standard (D198-

263 14) to provide a reference material strength for the test specimens used in this study. Steel

264 hinge supports at the load-bearing location were installed as load distributors to avoid

265 local failure. Web stiffeners were installed at support and force application locations to

266 avoid local web buckling failure. The ultimate flexural capacity test was conducted on 15 
267 I-joist specimens. It was observed that rupture tended to take place in regions with

268 inclined grain orientation and defects such as knots and splits. The average ultimate

269 flexural capacity was found to be $29.9 \mathrm{kNm}$ with a coefficient of variation (COV) of

$270 \quad 0.19$.

\section{Numerical analysis}

272 The FE models used here is similar to that described in the sensitivity analysis section.

273 The model accounts for the composite nature of the wood I-joist by using the mechanical

274 properties determined from the experimental program. An average flange St-Venant

275 shear modulus of $966 \mathrm{MPa}$, and a web modulus of elasticity of $3392 \mathrm{MPa}$ were used

276 based on the experimental component test results. The web shear modulus is assumed to

277 be $100 \mathrm{MPa}$, based on average values in the literature (Grandmont et al. 2008). A

278 concentrated load was symmetrically positioned at mid-span.

279 A nonlinear analysis was also conducted to describe the behaviour of the joists prior to

280 the ultimate buckling failure. The analysis is characterized by a nonlinear response of a

281 given system where the structure's stiffness varies with respect to the displacement.

282 When the structure's stiffness depends on the displacement, the initial stiffness can no

283 longer be multiplied by the applied load to determine the displacement and can be

284 expressed as:

$$
[K(v)]\{v\}=\{P\}
$$


286 where $[K(v)]$ denotes the stiffness matrix that is dependent on the nodal displacement $287\{v\}$ under loading $\{P\}$.

288 In ABAQUS, a nonlinear problem is solved incrementally with the Newton-Raphson 289 method (Simulia; 2012). This method solves for the single equilibrium path of a 290 nonlinear problem with an iterative process. The nonlinear relationship observed from the 291 experimental investigation of the wood I-joist critical buckling load can be primarily 292 attributed to geometric non-linearity. An eigenvalue buckling analysis were carried out to

293 provide an estimate of the critical buckling load, followed by a nonlinear analysis to 294 reproduce the lateral instability behavior of the wood I-joists observed during the 295 experiments. Modified Riks method was used to conduct a geometric nonlinear analysis, 296 which incorporated the measured initial imperfections on the wood I-joist, using the 297 preceding Eigen mode shape scaled to match the out-of-straightness of the top flange of 298 each test specimens.

\section{Discussion}

\section{Effect of length-to depth aspect ratio on component parameters}

301 Currently, no standardized procedure exists to specify the aspect ratio of span-to-depth 302 needed for testing wood I-joists. As part of the current study the effect of the span-to303 depth ratio on the torsional stiffness $(G J)$ was therefore investigated. As seen in Figure 8, 304 the results show that the span-to-depth ratio has a significant effect on the resulting 305 torsional stiffness $(G J)$. This effect is likely due to warping deformations which increase 
306 as the test span decreases. It can be observed from Figure 8 that, for the $0.4 \mathrm{~m}$ I-joist, the

307 torsional stiffness value stabilizes as the test configuration reaches a span-to-depth ratio

308 around 11.5. A similar level of span-depth ratio was not feasible for the $0.6 \mathrm{~m}$ I-joist since

309 the length of the specimens did not allow for a span-to-depth ratio larger than 9.5. The

310 trend observed in Figure 8 supports the deduction that a similar aspect ratio could also be

311 used for the $0.6 \mathrm{~m}$ joists. This assumption needs to be substantiated by future studies

312 before a general statement about suitable span-to-depth ratios can be made.

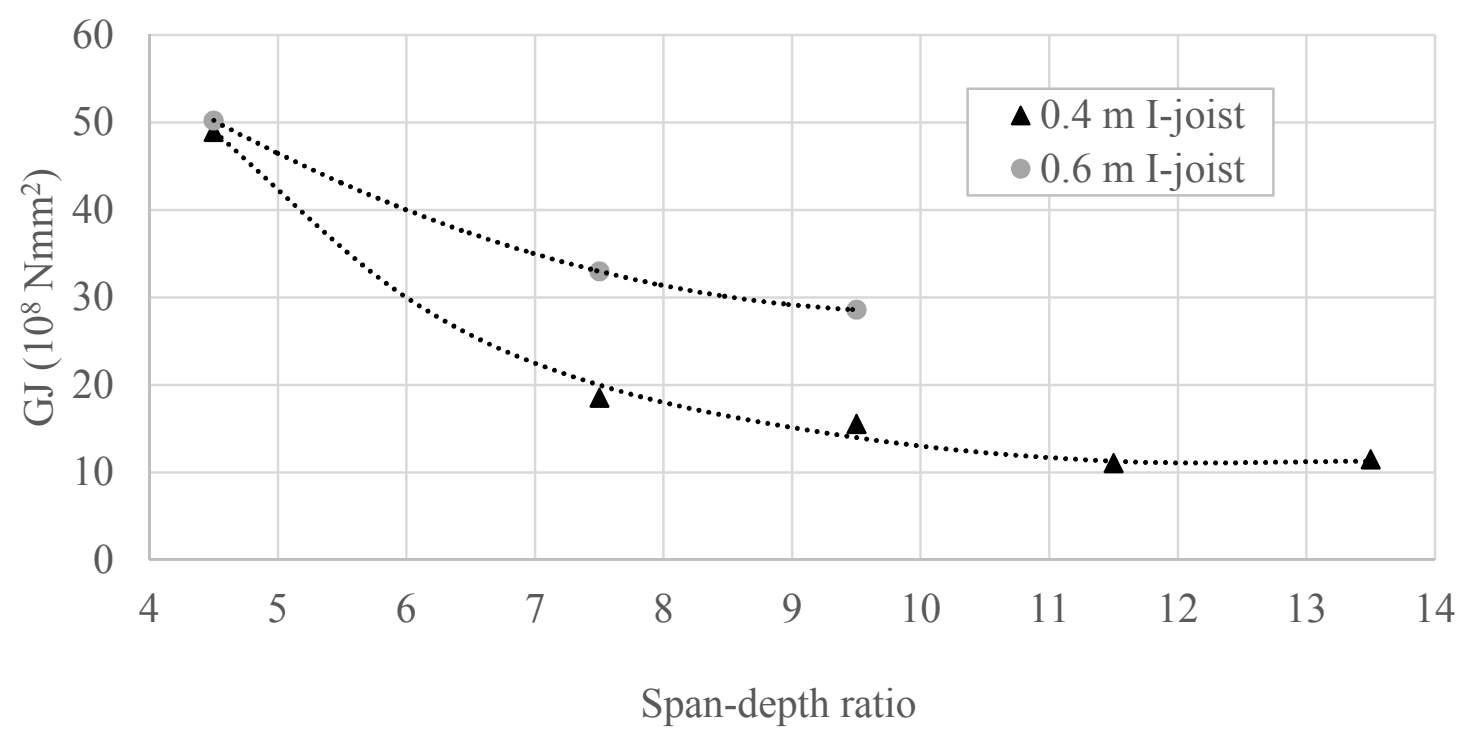

314 Figure 8 : Length study on the torsional rigidity of entire wood I-joist specimens

\section{Predicting the buckling behaviour of wood I-joists}

317 Figure 9 shows the comparison between the experimental results and those obtained from

318 the linear FE model and the analytical solution (Eq. 2). Both analysis methods yielded

319 critical buckling loads that were lower than the experimental capacity. As expected, the 
320 classical analytical model yielded higher predictions than the FE model. This can in part

321 be attributed to the fact that the analytical solution does not account for the distortion of

322 the web which, as mentioned in the sensitivity analysis section, can reduce the LTB

323 capacity. In general, both the FE analysis and the analytical solution seem to provide

324 appropriate and conservative estimates of the buckling loads.

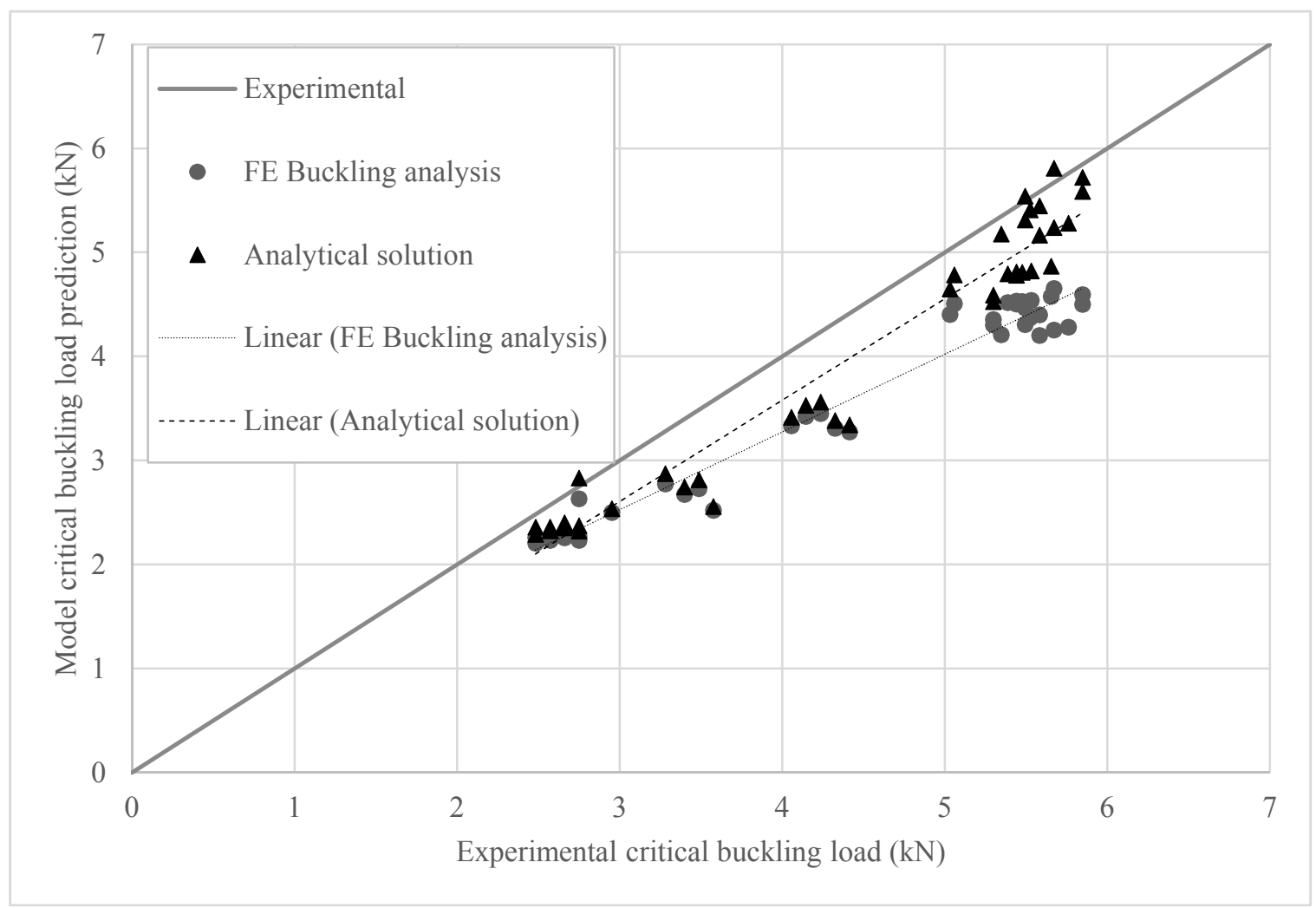

325 Figure 9: Experimental CBLs vs. model predictions for the wood I-joist specimens

327 Figure 10 shows comparison between the non-linear buckling analysis and the 328 experimental results. It can be observed that both the experimental angular displacement 329 and the experimental lateral displacement have similar stiffness relationships. It can also 330 be observed that the nonlinear FE model provides a reasonable estimate of the joist 
331 buckling behaviour when the effect of initial imperfections is included in the model. The

332 I-joist specimens' initial imperfection was measured as the out-of-straightness of the top

333 flange. The value was included in the non-linear analysis in such a way that the pre-

334 buckled shape of the joist in the model is the same as that measured in the test specimen.

335 The deviation between the FE analysis and the experimental results observed could be

336 attributed to the variation in material properties and accuracy in the estimate of the initial

337 imperfection. The sensitivity analysis showed that the initial imperfections appear to

338 affect the lower stiffness branch of the overall nonlinear behavior. Also, the measured

339 imperfections on the wood I-joist test specimens did not account for the initial twist at

340 mid-span, nor the out-of-straightness of the bottom flange, which could have led to more

341 discrepancy between test and modelling results.

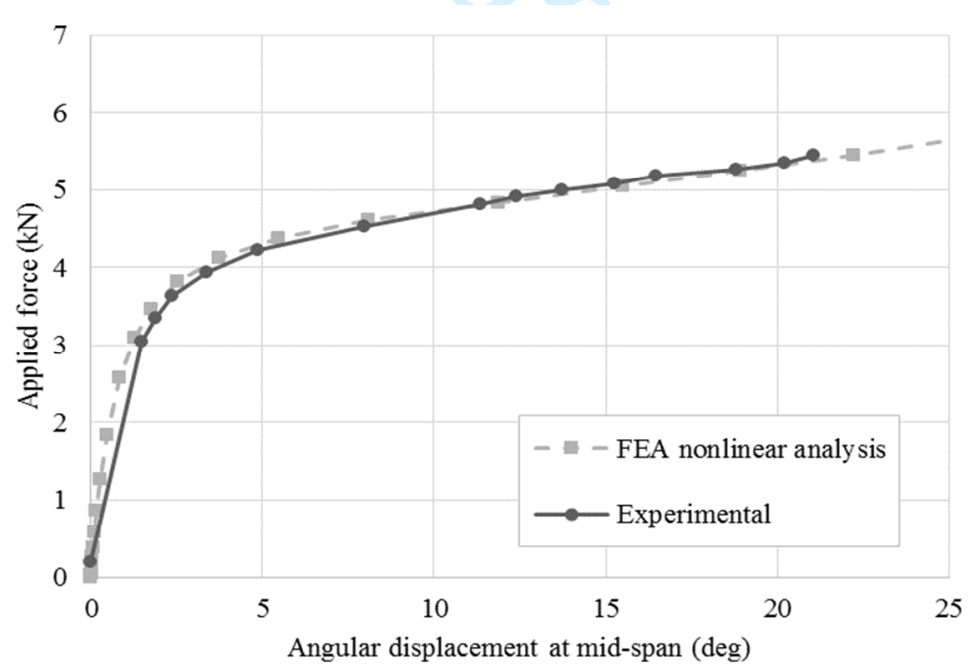

a) 


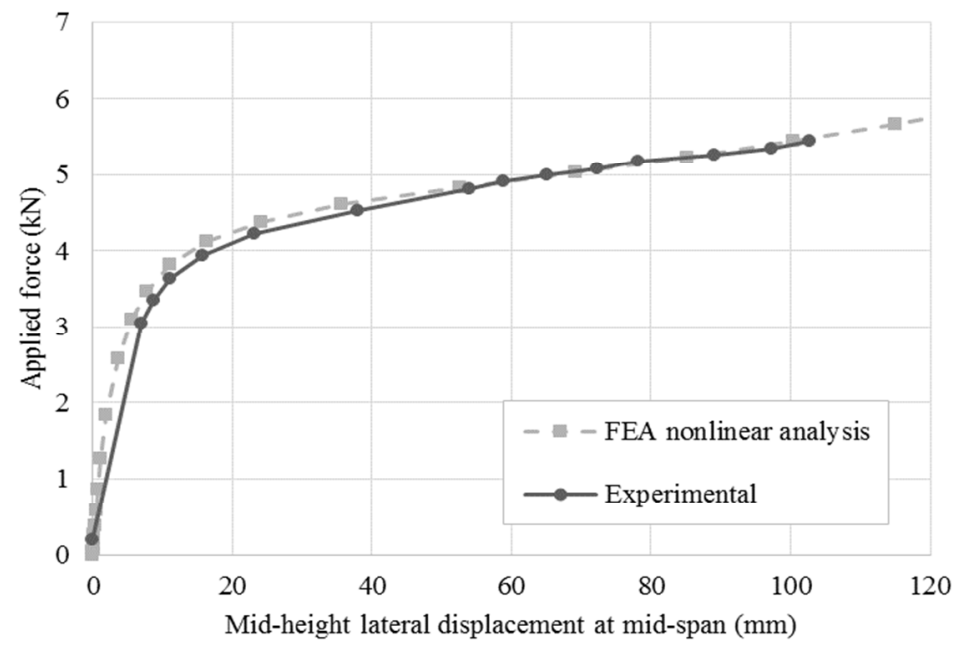

347 Figure 10 Buckling displacements of specimen 5-5. a) Angular displacement at mid-span and b) mid-height lateral displacement at mid-span

\section{Comparison with design standard}

350 Current provisions in the timber standards (CSA 2014; NDS 2015) only address the

351 design of wood I-joist members in a cursory manner. The American design standard and 352 the Canadian design commentary state that the material and geometric properties of only

353 the compression flange should be taken into account when performing lateral stability 354 calculations (NDS 2015; CWC 2014). This statement is partially supported by the FE 355 sensitivity analysis which showed that the most influential material parameter in lateral-

356 torsional buckling is found to be the longitudinal modulus of elasticity in the compression 357 flange. 
358 Moment gradient and eccentricity factors were derived using the FE model developed in 359 the current project and compared with those obtained using the AFPA approach (AFPA;

360 2003) in Figure 11. The AFPA factors were derived with the same values for the modulus

361 of elasticity, the shear modulus and the geometric properties used in the FE model which

362 considered a simply supported wood I-joist. Although the AFPA (2003) procedure for the

363 derivation of the eccentricity factors $\left(C_{e}\right)$ is based on a rectangular section and neglects

364 warping, it provides eccentricity factors that are similar to those derived with the FE

365 model. A small deviation is observed as the span-to-depth ratio diminishes, suggesting

366 that the warping effects are more pronounced as the model reaches smaller spans. The

367 derived moment gradient $\left(w_{2}\right)$ was almost constant with values ranging from 1.24 to 1.27

368 for a span to height ratio range of 8.5 to 14.5 . 


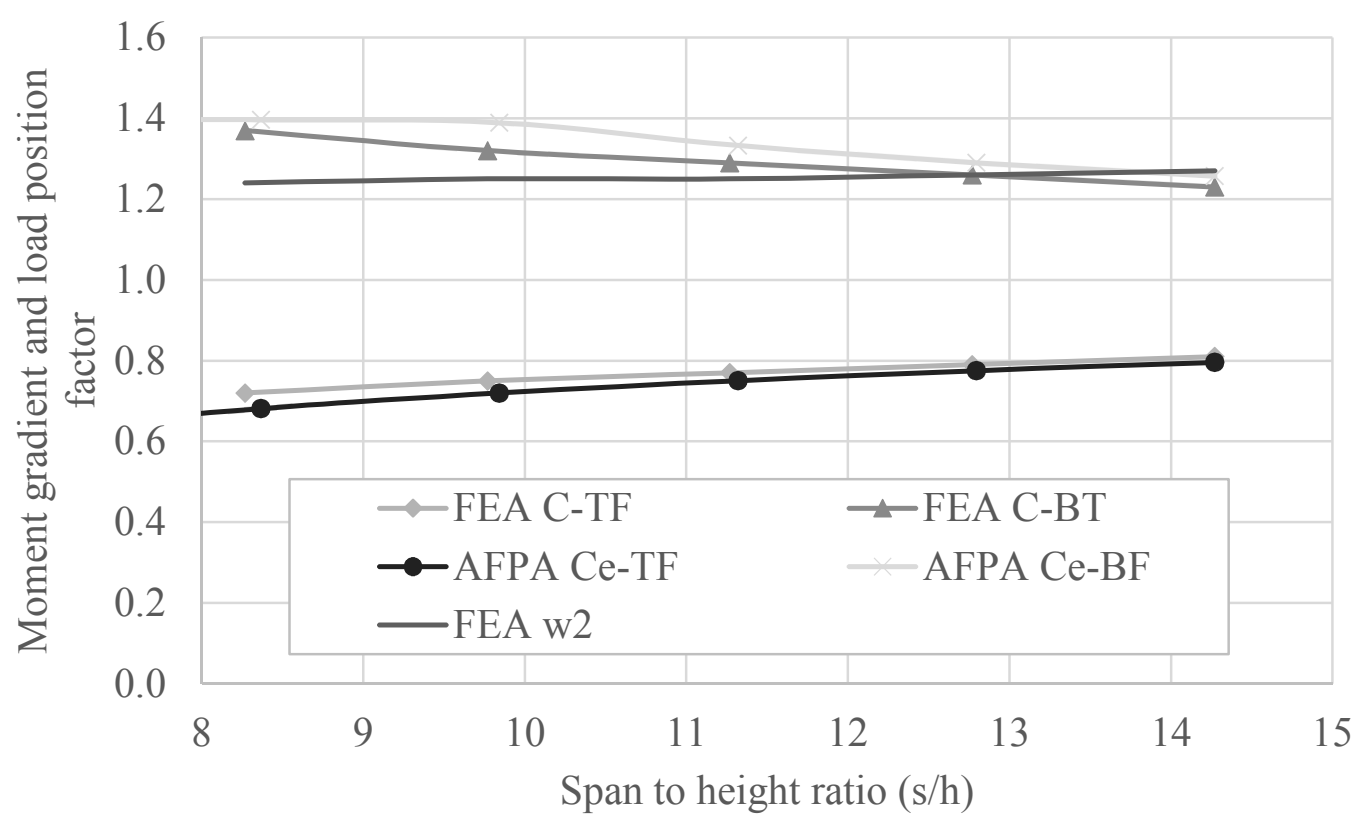

372 Figure 11: Comparison between FE and proposed moment gradient and load eccentricity factors

374 The ability of the NDS (2015) design method to predict the critical buckling load was

375 also investigated. Table 4 shows the comparison between the calculated buckling load

376 and those obtained experimentally.

377 Table 4: comparison between experimental buckling capacity and code predictions

\begin{tabular}{|c|c|c|c|c|c|}
\hline \multirow{2}{*}{$\begin{array}{c}\text { Sample } \\
\text { group }\end{array}$} & \multirow{2}{*}{ Specimen \# } & \multirow{2}{*}{$\begin{array}{c}\text { MOE } \\
\text { (MPA) }\end{array}$} & \multicolumn{2}{|c|}{ CBL (kN) } & \multirow{2}{*}{ NDS / Exp. } \\
\hline & & & Experimental & NDS & \\
\hline \multirow{10}{*}{5} & 1 & 12773 & 5.03 & 2.42 & 0.481 \\
\hline & 2 & 13545 & 5.53 & 2.56 & 0.463 \\
\hline & 3 & 13417 & 5.39 & 2.54 & 0.471 \\
\hline & 4 & 12233 & 5.30 & 2.32 & 0.438 \\
\hline & 5 & 13351 & 5.44 & 2.53 & 0.465 \\
\hline & 6 & 13372 & 5.06 & 2.53 & 0.500 \\
\hline & 7 & 13490 & 5.48 & 2.55 & 0.465 \\
\hline & 8 & 13756 & 5.66 & 2.60 & 0.459 \\
\hline & 9 & 12504 & 5.30 & 2.37 & 0.447 \\
\hline & 10 & 13505 & 5.44 & 2.55 & 0.469 \\
\hline
\end{tabular}




\begin{tabular}{|c|c|c|c|c|c|}
\hline & 1 & 12205 & 4.33 & 1.50 & 0.346 \\
\hline \multirow{4}{*}{6} & 2 & 13301 & 4.24 & 1.63 & 0.384 \\
\hline & 3 & 11950 & 4.41 & 1.47 & 0.333 \\
\hline & 4 & 12394 & 4.06 & 1.52 & 0.374 \\
\hline & 5 & 13095 & 4.15 & 1.61 & 0.388 \\
\hline \multirow{5}{*}{7} & 1 & 11335 & 3.58 & 0.88 & 0.246 \\
\hline & 2 & 13377 & 3.49 & 1.03 & 0.295 \\
\hline & 3 & 12813 & 3.40 & 0.99 & 0.291 \\
\hline & 4 & 13845 & 3.28 & 1.07 & 0.326 \\
\hline & 5 & 11161 & 2.95 & 0.86 & 0.292 \\
\hline \multirow{11}{*}{8} & 1 & 13706 & 2.57 & 0.74 & 0.288 \\
\hline & 2 & 14310 & 2.66 & 0.77 & 0.289 \\
\hline & 3 & 14223 & 2.75 & 0.76 & 0.276 \\
\hline & 4 & 14068 & 2.48 & 0.75 & 0.302 \\
\hline & 5 & 13696 & 2.75 & 0.74 & 0.269 \\
\hline & 6 & 19282 & 2.75 & 1.03 & 0.375 \\
\hline & 7 & 14537 & 2.66 & 0.78 & 0.293 \\
\hline & 8 & 13742 & 2.57 & 0.74 & 0.288 \\
\hline & 9 & 14066 & 2.57 & 0.75 & 0.292 \\
\hline & 10 & 14028 & 2.66 & 0.75 & 0.282 \\
\hline & 11 & 13370 & 2.48 & 0.72 & 0.290 \\
\hline \multirow{11}{*}{16} & 1 & 13490 & 5.67 & 3.73 & 0.658 \\
\hline & 2 & 11393 & 5.35 & 3.16 & 0.591 \\
\hline & 3 & 12160 & 5.53 & 3.37 & 0.609 \\
\hline & 4 & 11735 & 5.76 & 3.25 & 0.564 \\
\hline & 5 & 11357 & 5.58 & 3.15 & 0.565 \\
\hline & 6 & 11846 & 5.50 & 3.28 & 0.596 \\
\hline & 7 & 11597 & 5.67 & 3.22 & 0.568 \\
\hline & 8 & 12286 & 5.58 & 3.40 & 0.609 \\
\hline & 9 & 12753 & 5.85 & 3.53 & 0.603 \\
\hline & 10 & 12593 & 5.50 & 3.49 & 0.635 \\
\hline & 11 & 13204 & 5.85 & 3.65 & 0.624 \\
\hline
\end{tabular}

379 The design standard provided predictions of the critical buckling loads that were in the

380 range of 34 to $75 \%$ smaller than the experimental capacity. These results expose the high

381 conservatism found in the design standard. The approach used in the design standard

382 seems too simplistic as it substitutes the lateral buckling of the wood I-joist by simple 
383 column bucking of compression flange restrained in the plane of the web. The design

384 standard clearly neglects the restoring action effect of the tension flange on the critical

385 buckling load and the torsional resistance provided by the warping of the I-joist cross-

386 section.

387 A methodology to determine the lateral buckling capacity of wood I-joists using the 388 analytical solution found in Eq. 2, and modified for moment gradient and load 389 eccentricity factors (AFPA 2003) is presented next. The analytical solution can take the

390 following form;

$$
M_{c r}=C_{b} C_{e} \frac{\pi}{L} \sqrt{E I_{y} G J+\left(\frac{\pi E}{L}\right)^{2} I_{y} C_{w}}
$$

392 Where $C_{b}$ is a moment gradient factor and $C_{e}$ is the load eccentricity factors.

393 In order to compare the numerical example presented here with results obtained

394 experimentally, a test specimen consisting of $38 \times 64 \mathrm{~mm}$ flanges, $9.53 \mathrm{~mm}$ thick web

395 section height of $406 \mathrm{~mm}$ and a span $\left(l_{u}\right)$ of $3970 \mathrm{~mm}$ is considered. A concentrated load

396 is assumed to be applied at mid-span. The average values of the elastic and shear

397 modulus determined from component testing for sample group \#5 are 12,800 MPa and

$398966 \mathrm{MPa}$, respectively. The moment gradient factor, $C_{b}$, is computed as (AFPA 2003):

$$
C_{b}=\frac{1,25 M_{\max }}{2,5 M_{\max }+4 M_{A}+3 M_{B}+3 M_{C}}
$$


400 Where $M_{A}$ is the absolute value of the moment at $\mathrm{L} / 4, M_{B}$ is the absolute value of the 401 moment at $\mathrm{L} / 2$ and $M_{C}$ is the absolute value of the moment at $3 / 4 \mathrm{~L}$. Having $M_{A}=M_{C}=$ $4022 M_{B}=M_{\max }, C_{b}$ is calculated as 1.32 .

403 The AFPA expression for the load eccentricity factor is as follows:

404

$$
C_{e}=\sqrt{\left(\frac{k d}{2 l_{u}} \sqrt{\frac{E I_{y}}{G J}}\right)^{2}+1}-\frac{k d}{2 l_{u}} \sqrt{\frac{E I_{y}}{G J}}
$$

405 Where $k$ is given as 1.72 (AFPA; 2003).

406 The resulting $C_{e}$ is 0.82 . The web contribution in determining the geometrical properties

407 of the section $\left(I_{y}, J\right.$ and $\left.C_{w}\right)$ is found to be negligible. The computed moment of inertia 408 about the weak axis calculated using only the properties of flanges was found to be $1.62 \mathrm{x}$ $40910^{6} \mathrm{~mm}^{4}$. Neglecting the web contribution, the warping constant $\left(C_{w}\right)$ of an I-section 410 (Gjelsvik 1981) with thick flanges is $C_{w}=\left\{I_{y} d^{\prime 2} / 4\right\}+\left\{2 t^{3} b^{3} / 144\right\}$, where $\mathrm{b}$ is the 411 flange width, $d^{\prime}$ is the web height taken between flange centroids, $t$ is the flange thickness 412 and $I_{y}$ the moment of inertia about the weak axis. An approximate form for the St-Venant 413 torsional constant $J_{e}=\sum_{i=1,2,3 \ldots}\left(\frac{b_{i} h_{i}^{3}}{\emptyset}\right)$ was proposed by Kirby and Nethercot (1979), 414 where $b$ is the width, $h$ the height and $\varnothing$ is 4.85 for a flange cross-section of $38 \times 63.5$ $415 \mathrm{~mm}$. The resulting warping constant and St-Venant torsional constant of the flanges are 416 computed to be $5.52 \times 10^{10} \mathrm{~mm}^{6}$ and $1.44 \times 10^{6} \mathrm{~mm}^{4}$, respectively. 
417 Using these inputs, the resulting critical load applied at mid-span can be determined to be

$4185.29 \mathrm{kN}$. This value is considered reasonably close to the experimental lateral buckling 419 load of specimen group \#5, i.e. $5.36 \mathrm{kN}$.

420 The above example illustrate that the proposed procedure can be used to estimate the

421 lateral torsional buckling capacity of wood I-joists with reasonable accuracy. It should be

422 noted that the example is based on average values in order to compare with the test

423 results. The approach used to determine the design level safety factor for the buckling

424 failure is different for different standards and therefore no attempt was made here to 425 suggest what the design level capacity should be. Instead the validity of the approach is 426 demonstrated and it is left to the appropriate code and standard committees to debate the 427 level of safety needed.

\section{Conclusions}

429 The conclusions that can be drawn from the current study are summarized as follows:

430 1) A sensitivity analysis was conducted on the mechanical properties of wood I431 joists and it revealed that the most influential mechanical properties are the 432 longitudinal modulus of elasticity and the torsional shear modulus of the 433 compression flange. To a lesser extent, these same properties in the tension flange 434 and the transverse modulus of elasticity of the web also impact the buckling $435 \quad$ response. 
436 2) The lateral flexural stiffness test of the entire I-joist and the torsion test on the 437 flange alone were found to be appropriate and provide adequate input parameters 438 for the analytical models.

439 3) The FE linear predictions were found to be in reasonable agreement with the 440 experimental buckling loads. The FE geometric nonlinear analysis incorporated 441 the initial imperfection into the models and was able to replicate the experimental 442 nonlinear behavior that was observed during the test.

443 4) The Analytical solution for lateral torsional buckling of I-beam can provide a 444 conservative estimate of the critical buckling load of simply supported wood I445 joist providing that proper moment gradient and load eccentricity factors are used.

5) The NDS model provided predictions that were 34 to $75 \%$ smaller than the experimental lateral torsional buckling failure load, which shows significant conservatism in the approach. An approach based on the classical solution modified for moment gradient and load eccentricity factors was presented to demonstrate a possible methodology to design I-joists for lateral torsional buckling failure.

\section{REFERENCES}

453 American Forest \& Paper Association 2003. Designing for lateral torsional buckling in 454 wood members, Technical report, AWC. Washington, DC, USA.

455 Aguilar, J. M. V. 2012. Lateral torsional Buckling Instability Caused by Individuals Walking on Wood Composite I-Joists. Doctoral thesis, Virginia Polytechnic Institute and State University, Blacksburg, Virginia, USA.

458 American Institute of Steel Construction. 2010. Specification for Structural Steel 
American society for testing materials. 2002. ASTM D2719 Standard test methods for

Structural Panels in Shear Through-the-Thickness.
$<$ https://www.astm.org/Standards/D2719.htm $>$ (Dec, 14, 2015)

American society for testing materials. 2003. ASTM D4761 Standard Test Methods for

American society for testing materials. 2007. ASTM D7033 Standard Practice for Establishing Design Capacities for Oriented Strand Board (OSB) Wood-Based Structural-Use Panels. <https://www.astm.org/Standards/D7033.htm> (Aug, 18, 2015)

American society for testing materials. 2011. ASTM D2718 Standard Test Methods for structural panels in planar shear (rolling shear). $<$ https://www.astm.org/Standards/D2718.htm> (Jul, 27, 2015)

American society for testing materials. 2011. ASTM D3043 Standard Test Methods for Structural Panels in Flexure. <https://www.astm.org/Standards/D3043.htm> (Jul, 27, 2015)

American society for testing materials. 2012. ASTM D198 Standard Test Methods of Static Tests of Lumber in Structural Sizes. $<$ https://www.astm.org/Standards/D198.htm> (Jan, 14, 2015)

American society for testing materials. 2013. ASTM D5055 Standard Specification for Establishing and Monitoring Structural Capacities of Prefabricated Wood I-Joists. $<$ https://www.astm.org/Standards/D5055.htm> (Apr, 10, 2015)

Ascione, F. 2014. Influence of initial geometric imperfections in the lateral buckling problem of thin walled pultruded GFRP I-profiles. Composite Structures, 112(1), 85-99.

487 Bamberg, C. R. 2009. Lateral movement of unbraced wood composite I-joists exposed to 488 dynamic walking loads. Master thesis, Virginia Polytechnic Institute and State 489 University, Blacksburg, Virginia.

490 Bell, K., \& Eggen, T. even. 2001. Stability of timber beams and columns. In Innovative 491 wooden structures and bridges : IABSE Conference Lahti 2001 (pp. 155-161). 
492 Buchanan, A. H. 1986. Combined Bending and Axial Loading in Lumber. Journal of 493 Structural Engineering, 112(12), 2592-2609. (ASCE)0733-9445(1986)112:12(2592)

494 Burow, J. R., Manbeck, H. B., \& Janowiak, J. J. 2006. Lateral stability of composite 495 wood I-joists under concentrated load bending. American Society of Agricultural and Biological Engineers, 49(6), 1867-1880.

Canadian Standard Association. 2014a CSA-S16-09 Engineering design in wood. Mississauga, Ontario, Canada.

Canadian Standard Association. 2014b CSA-086-09 Design of steel structures. Mississauga, Ontario, Canada.

Cheng et al., J. et al. 1988. Lateral buckling tests on coped steel beams. Journal of Structural Engineering, 114(1), 16-30.

Canadian Wood Council, 2014. Wood Design Manual. Nepan, Ontario, Canada

Dabbas, A. 2002. Stability of laterally unsupported wide-flange structure. Master thesis, Ottawa-Carleton Institute, Ottawa, Ontario, Canada.

Du, Y. 2016. Lateral Torsional Buckling of Wooden Beam-Deck Systems. Master thesis, Ottawa-Carleton Institute, Ottawa, Ontario, Canada.

Du, Y, Mohareb M., Doudak D 2016 Lateral Torsional Buckling of Twin-beam deck assemblies under wind uplift-sway versus non-sway models, World conference in timber engineering, Vienna Austria, Aug. 22-25

511 Forest Laboratory Products 2010. Wood Handbook, General technical report FPL-GTR190. United States Departement of Agriculture, Madison, Wisconsin, USA.

513 Gjelsvik, A. 1981. The Theory of Thin Walled Bars. Journal of Applied Mechanics 49(2).

514 Grandmont, J. 2011. Analyse structural du système âme-semelles de poutrelles en bois. 515 Doctoral thesis, Université Laval, Montréal, Québec, Canadaé

516 Grandmont, J.-F., Desjardins, R., Cloutier, A., \& Gendron, G. 2008. Measurement of 517 OSB properties and their variability for modeling purposes. 10th World Conference 518 on Timber Engineering 2008, 4, 2054-2060.

519 Gupta, R., \& Siller, T. S. 2005a. A comparison of the shear strength of structural 520 composite lumber using torsion and shear block tests. Forest Products Journal, $521 \quad 55(12), 29-33$.

522 Gupta, R., \& Siller, T. S. 2005b. Stress distribution in structural composite lumber. Wood 
Science, 55(9753), 51-56.

524

525

526

527

528

529

530

531

532

533

534

535

536

537

538

539

540

541

542

543

544

545

546

547

548

549

550

551

552

553

554

555

Hassan, R. and Mohareb, M. 2015, Distortional lateral torsional buckling for simply supported beams with web cleats, Journal of Civil of Civil Engineering, 42, 10911103.

Hindman, D. P. 2003. Torsional rigidity and lateral stability of structural composite lumber and I-joists members. Doctoral thesis, Pennsylvania State University, Pennsylvania, USA.

Hindman, D. P., Bamberg, C. R., \& Nussbaum, M. A. 2010. Bracing of wood composite I-joists to resist lateral buckling from walking loads. ASCE, 8(3), 1397-1403.

Hindman, D. P., Manbeck, H. B., \& Janowiak, J. J. 2003. Torsional Rigidity and Lateral Stability of SCL and I-joist Beams. American Society of Agricultural and Biological Engineers, 0300(03).

Hindman, D. P., Manbeck, H. B., \& Janowiak, J. J. 2005a. Measurement and Prediction of Lateral Torsional Buckling Loads of Composite Wood Materials: Rectangular Sections. Forest Products Journal, 55(9), 42-47.

Hindman, D. P., Manbeck, H. B., \& Janowiak, J. J. 2005b. Measurement and Prediction of Lateral Torsional Buckling Loads of Composite Wood Materials: I-Joist Sections. Forest Products Journal, 55(10), 43-48.

Isopescu, D., Stanila, O., and Asatanei, I. 2012. Analysis of Wood Bending Properties on Standardized Samples and Structural Size Beams Tests, Buletinul Insititutului PolitehnicDIN Din Iasi, Publicat de Universitatea Tehnica, Gheorghe Asachi' Din Iasi

Hooley, R. F. and Madsen, B. 1964. Lateral Buckling of Glued Laminated Beams, Journal of Structural Engineering Division, ASCE, Vol. 90, No. ST3, pp. 201-303.

Kala, Z. 2013. Elastic lateral torsional buckling of simply supported hot-rolled steel Ibeams with random imperfections. In Procedia Engineering (Vol. 57, pp. 504-514). Elsevier B.V.

Kirby, P. A. and Nethercot, D. A. 1979. Design for Structural stability. Constrado Monographs, Granada Publishing, Suffolk, UK.

Liang, K., Ruess, M., \& Abdalla, M. 2014. The Koiter-Newton approach using von Karman kinematics for buckling analyses of imperfection sensitive structures. Computer Methods in Applied Mechanics and Engineering, 279, 440-468.

Link, R., Link, R., Gupta, R., Heck, L., \& Miller, T. 2002. Experimental Evaluation of 
the Torsion Test for Determining Shear Strength of Structural Lumber. Journal of Testing and Evaluation, 30(4), 283.

Machado, S. P. 2010. Non-linear stability analysis of imperfect thin-walled composite beams. International Journal of Non-Linear Mechanics, 45(2), 100-110.

Mandal, P., \& Calladine, C. R. 2002. Lateral torsional buckling of beams and the Southwell plot. International Journal of Mechanical Sciences, 44(12), 2557-2571.

Markiz, N. 2011. Experimental investigation of the lateral torsional buckling of Gerber Frames. Master thesis, Ottawa-Carleton Institute, Ottawa, Ontario, Canada

Memon, B.-A., \& Su, X. 2004. Arc-length technique for nonlinear finite element analysis. Journal of Zhejiang University SCIENCE. 5(5), 618-628.

National Design Standard for wood construction, NDS 2015. American Wood Council, 2015 Edition, Leesburg, Virginia.

New Steel Construction. 2006. Lateral torsional buckling and slenderness. NCS (Vol. 14). $<$ http://www.newsteelconstruction.com/wp/wpcontent/uploads/TechPaper/NSCOct06_Tech.pdf $>$ April 1 ${ }^{\text {st }}, 2016$.

Pham, P. Van, \& Mohareb, M. 2014b. Thin-Walled Structures A shear deformable theory for the analysis of steel beams reinforced with GFRP plates. Thin-Walled Structures, $85,165-182$.

Simulia. 2012. ABAQUS/CAE User's Manual (Version 6.12), Dassault Systemes.

Southwell, R. 1931. On the analysis of experimental observations in problems of elastic stabililty. Proceedings of the Royal Society of London, 268, 527.

Suryoatmono B. and Tjondro A. 2008. Lateral torsional Buckling of Orthotropic Rectangular Section Beams. Department of Civil Engineering, Parahyangan Catholic University, Bandung, Indonesia.

Thomas, W. H. 2001. Mechanical properties of structural-Grade oriented strand board. Holz Als Roh- Und Werkstoff, 59(6), 405-410.

Timoshenko, S., \& Gere, J. 1961. Lateral Buckling of Beams. Journal of the Structural Division, 86, 175-196.

Vensko, M. J. 2008. Lateral torsional buckling of structures with monosymmetric crosssections. Master thesis, Pennsylvania State University, Pennsylvania, USA.

Vlasov, V. Z. 1961. Thin-walled elastic beams, $2^{\text {nd }}$ edition, Israel program for scientific 
transanctions, Jerusalem.

588 Westlund, J. 2013. Lateral Torsional Buckling of I-beams. Master thesis, Chalmers 589 University of Technology, Goteborg, Sweden, Europe.

590 Xiao, Q. 2014. Lateral Torsional Buckling of Wood Beams. Master thesis, OttawaCarleton Institute, Ottawa, Ontario, Canada

592 Xiao, Q., Doudak, G., \& Mohareb, M. 2014. Lateral Torsional Buckling of Wood Beams: 593 FEA-Modeling and Sensitivity Analysis, WCTE, Quebec. 1-8.

594 Yang, Z. 2012. Torsional shear strength and size effect in structural composite. Master 595 thesis, University of Massachusetts, Massachusetts, USA.

596 Zahn, J. J. 1973. Lateral stability of wood beam-and-deck systems. Journal of Structural 597 Division, 51(July), 1391-1409.

598 Zhu, E. C., Guan, Z. W., Rodd, P. D., \& Pope, D. J. 2006. Buckling of Oriented Strand Board Webbed Wood I-Joists. Journal of Structural Engineering, 131(10), 1629$600 \quad 1636$.

601

602

603

604

605 